\title{
Research on Internal Consistency Based on Reliability Coefficient and Computer Simulation Technology
}

\author{
Chang Xie, Hongguang Lu, Yanru Xu, Yunjing He \\ China University of Geosciences, Wuhan, China \\ x_ie_chang@126.com
} Keywords: reliability coefficient; internal consistency; questionnaire survey; environmental
protection system; tax administration; wuhan

\begin{abstract}
Environment tax is a mandatory economic means that can effective promote environmental protection and ensure sustainable economic development, however at present China tax collection and management is not paid enough attention to the environment tax, which will adversely affect on the forthcoming introduction of environmental tax collection and management. From the Chinese environmental toll collection author, starting from the collection and management of Chinese current environment-related charges, combined with the actual research data in the 21 tax-related departments and 42 small, medium and large enterprises of a province a city 7 districts (counties), drawing lessons from domestic and international environmental tax collection and management experience, according to the China environment tax and environmental protection related fees' collection and management status and problems, it is obtained by environment, taxation and other departments fee and tax separation of the collection and management model is not suitable for the sustainable development strategy and the 12th Five-Year Plan conclusion.
\end{abstract}

\section{Introduction}

In the 1970s, OECD has proposed the polluter pays principle (Referred to as the PPP principle). Provisions on the environmental pollution caused by all economic entities, including unit and individual operators, which should be in accordance with relevant regulations and standard to undertake certain costs, it can encourage polluters consciously regulate own environmental pollution behavior, such as German waste tax's collection targets as any discharge wastewater, including citizens individual, public corporations [1]; Japan carbon tariff is a unit with the family collection, the amount of household is average and annual burden of 2100 yen [2]; Holland fuel tax's payer is mainly gasoline, liquefied petroleum gas, coal, natural gas, fuel oil and other major producers and importers, the core of this principle is to require all polluters must pay for environmental pollution behavior that bring in negative externality directly or indirectly, as a result, it can realize price mechanism to achieve environmental economy, so as to achieve efficient allocation of environmental resources.

In the majority of levying environment tax country, environmental tax collection are generally dedicated to protect and improve environment's measures. In German, only small portion waste taxes are used for compensation management on water resources fee, however mostly are established waste water or other pollutants treatment facilities or pollution control equipment, technology research and development, and the training personnel of related equipment operating expenses [3]. In addition, each country is not fulfill their obligations to pay taxes or related personnel, on the basis of illegal properties or polluting degree are provided with corresponding administrative liability or criminal liability.

From the implementation effect of environmental tax, it can be seen that the states have achieved significant results in the levying environmental taxes. Sweden began to a sulfur dioxide tax (\$3050), after a year, sulfide emissions are decreased by $16 \%$, and since the sulfur tax, oil sulfur content was reduced by $40 \%$, sulfur emissions of coal and mud also have a considerable degree of reduction. Since Germany water pollution tax began collection, annual tax had in the hundreds of millions of euros that were all as the local income to improve the water quality, social and environmental benefits $[4,5]$. 


\section{Research objects and methods}

As a study area in the central region of China, combined with questionnaire and interview surveys to carry out random sample survey on a province city, there are 21 government related-departments and 42 small and medium-sized enterprises of a certain area, a high-tech district and other 7 districts (counties) that are collected, at the same time a district state taxation, tax bureau and environmental protection agency are also visited, there are 30 related person that are carried out face-to-face indepth interviews, to gain first hand line data as seen in Table 1 [6].

\begin{tabular}{|l|l|l|l|l|}
\multicolumn{1}{c|}{ TABLE I. } & \multicolumn{4}{c|}{ Questionnaire investigation object's data analysis } \\
\hline & $\begin{array}{c}\text { The total number of } \\
\text { copies }\end{array}$ & $\begin{array}{c}\text { Recovery } \\
\text { copies }\end{array}$ & $\begin{array}{c}\text { Effective } \\
\text { copies }\end{array}$ & $\begin{array}{c}\text { Effective } \\
\text { recovery }\end{array}$ \\
\hline Recovery copies & 300 & 288 & 284 & $94.67 \%$ \\
\hline
\end{tabular}

Reliability is used to degree of the reliability of test questionnaire, which usually uses reliability coefficient to carry out represent, the reliability coefficient formula is [7]:

$$
R_{x x}=\frac{S T 2}{S x 2}
$$

$S T 2$ is said the true variance; $S x 2$ is said monthly variance, this result can be obtained according to the statistical software SPSS. Using a coefficient carries out internal consistency test [8], the formula is:

$$
\alpha=\left(\frac{k}{k-1}\right)\left(1-\frac{\sum S i 2}{S x 2}\right)
$$

$k$ is expressed as the total scores of test problems; $\mathrm{Si} 2$ is expressed as a problem score variance; $S \times 2$ is expressed as all test score variance.

Questionnaire survey content is on the basis of the person in charge of the enterprise, government officials and experts to analyze and understand, adopting the questionnaire reliability and validity analysis, the unrelated problems are rejected, and the test result is that the corresponding coefficient of reliability test should be greater than 0.8 , and under the condition of $\mathrm{P}<0.01$, which are all highly significant status, this fully indicates that the questionnaire credibility is relatively high, so it is more suitable for research [9].

Selecting the mathematical statistics method to carry out data comparative analysis, first of all is to set up the sample $y$ is the total number of $k$, then to carry out vector set for each sample data, namely q element vector has $\mathrm{m}$, i.e. observation data vector is $\mathrm{qm}$.

$$
\begin{array}{ccccccc}
\text { Sample } & V & a & l & u & e & \bar{y} \\
1 & y_{11} & y_{12} & \cdot & y_{1 n} & \cdot & \overline{y_{1}} \\
2 & y_{21} & y_{22} & \cdot & y_{2 n} & \cdot & y_{2} \\
\cdot & \cdot & \cdot & \cdot & \cdot & \cdot & \cdot \\
\cdot & \cdot & \cdot & \cdot & \cdot & \cdot & \cdot \\
\cdot & \cdot & \cdot & \cdot & \cdot & \cdot & \cdot \\
k & k_{k 1} & k_{k 2} & \cdot & k_{k n} & \cdot & \overline{y_{k}}
\end{array}
$$

Each observation date vector is given as follows:

$$
y_{j i}=\left(\begin{array}{l}
y_{j i 1} \\
y_{j i 2} \\
\ldots \\
y_{j i q}
\end{array}\right)=\mu+\tau_{j}+f_{j i} \quad\left\{\begin{array}{l}
j=1,2, \ldots, k \\
i=1,2, \ldots, m
\end{array}\right.
$$

The above expression decomposition model can be expressed as:

$\mathrm{y}_{\mathrm{ji}}=\overline{\mathrm{y}}+\left(\overline{\mathrm{y}}_{j}-\overline{\mathrm{y}}\right)+\mathrm{y}_{\mathrm{ji}}-y_{j}$

$y_{j i}$ is said observation data of sample $\mathrm{y} ; \bar{y}$ is said sample mean that is expressed as $\hat{\mu} ; \overline{y_{j}}-\bar{y}$ is said treatment effect estimates that is expressed as $\hat{\tau}_{i} ; y_{j i}-y_{j}$ is said residual value that is expressed as $\hat{e_{i j}}$. 


\section{Research on China current environmental-related tax collection and management problems}

For existing environmental-related taxes to the collection and management attitude different, it not only causes the different understanding and experience of tax collection and management behavior, and the correct attitude is associated with environmental protection behavior that can be a long lasting power of continuously development, it can be seen in Table 2.

TABLE II. China's current environment-related taxes collection and management awareness

\begin{tabular}{|l|l|l|l|l|l|}
\hline & $\begin{array}{c}\text { Very } \\
\text { familiar }\end{array}$ & $\begin{array}{c}\text { Better } \\
\text { understanding }\end{array}$ & General & $\begin{array}{c}\text { Not } \\
\text { understand }\end{array}$ & $\begin{array}{c}\text { Very not } \\
\text { understand }\end{array}$ \\
\hline Number of people & 47 & 97 & 59 & 46 & 35 \\
\hline Proportion & $16.55 \%$ & $34.15 \%$ & $20.77 \%$ & $16.20 \%$ & $12.32 \%$ \\
\hline
\end{tabular}

In Table 2, understanding of the existing environment-related taxes on collection and management can be seen that relatively very understanding and the proportion of a better understanding have reached $50.7 \%$, accounted for the first row as better understanding that is $34.15 \%$; followed by general ratio that is $20.77 \%$; the last don't very like that is accounted for ratio of $12.32 \%$. There are $16.55 \%$ people that are very familiar with China's current environmentalrelated taxes collection policy, however overall, the Chinese people on the understanding of current environment tax collection is not enough, to be further improved. It can be seen in Figure 1.

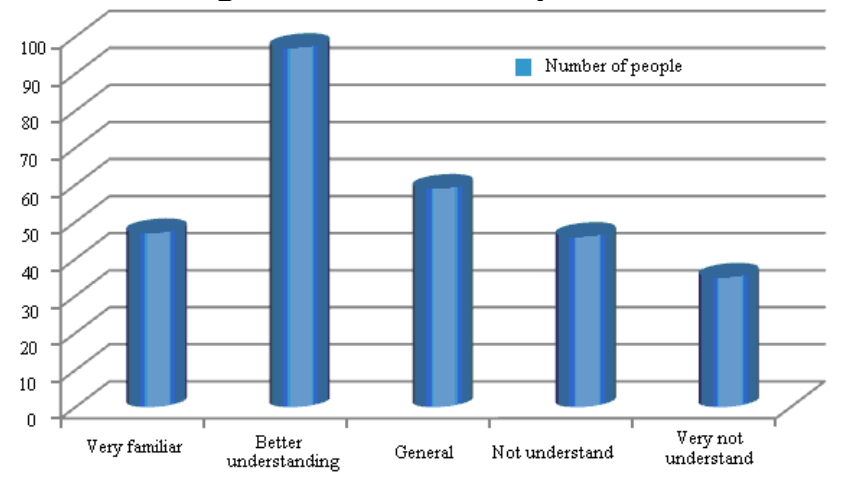

Figure 1. People on China's current environmental-related taxes collection and awareness

From the obtained data analysis, it can be seen that China's current pollution charges system defects exist some problems: pollution charges policy has early put forward in 1978, so far has become the most widely used environmental economic policy $[10,11]$. The implementation of the sewage charges have been more than 20 years, the use of sewage charges funds have a significant role in China environmental protection, this role is mainly embodied in the increase of pollution governance capacity, at the same time to strengthen the construction of environmental protection system. However, in the process of operation, there are also some problems. The specific performance is shown in Table 3 and in Figure 2.

TABLE III. Chinese current pollution charge system defect analysis

\begin{tabular}{|c|c|c|}
\hline & The number of people & Proportion \\
\hline $\begin{array}{c}\text { Pollution discharge fee standard is too low and the } \\
\text { collection efficiency is not high }\end{array}$ & 100 & $18.98 \%$ \\
\hline Pollution charge team capability is not strong & 50 & $9.49 \%$ \\
\hline Effluent charge whereabouts unknown & 83 & $15.75 \%$ \\
\hline The collection of sewage charges with a lag & 67 & $12.71 \%$ \\
\hline Other & 16 & $3.04 \%$ \\
\hline
\end{tabular}

In Table 3 and Figure 2, they can be seen that the existing pollution charge system has pollution discharge fees too low, collection efficiency not-high, sewage charges team capability not strong, sewage charges capital unidentified, sewage fee collection with a lag and other defects. (1) Pollution discharge fees standard is too low and the collection efficiency is not high, accounted for more than $18.98 \%$ [12]. Pollution charge standard is very low, however management cost is more and more high, which is very small for the polluting enterprises stimulation effects. In the actual statistical work of pollution discharge declaration and registration, there are also false, deceptive reports and other phenomena, resulting in the collection of sewage charges is insufficient; according to the survey, there are $63.4 \%$ of government staff that thinks collects inadequacy; $48.8 \%$ of the government staff points out that has 0 - $20 \%$ of the funds was required to turn over at a local excess retention ratio, the environmental protection charging system still exists theoretical and practical problems; (2) Pollution charge team capability is not strong, accounted for 9.49\%. Taking a certain 
city as an example, our field survey can be seen that environmental protection departments due to lack of sufficient preparation, manpower, professional equipment lag and law enforcement personnel related professional knowledge uneven, which will seriously affect charging work; (3) The effluent charge is an unknown destination, accounted for more than $15.75 \%$. Due to the lack of effective supervision, environmental protection funds do not fulfill, collection up funds exists in eat sewage charges phenomenon, law enforcement capacity is affected; (4) Sewage fee collection has lagged behind, accounted for more than $12.71 \%$. Compared with the developed countries in the world, China for environmental monitoring method is equipment backward, lack of technology and testing personnel quality is different, so the enterprises are lack of the necessary monitoring and management. When the discharge amount exceeds the safety range, the environmental protection department prepares the relevant collection expenses that are in view of the enterprise to develop, the enterprise more polluted areas have been destroyed, and the area of governance cost is far higher than the collection of sewage charges, so it has serious lag.

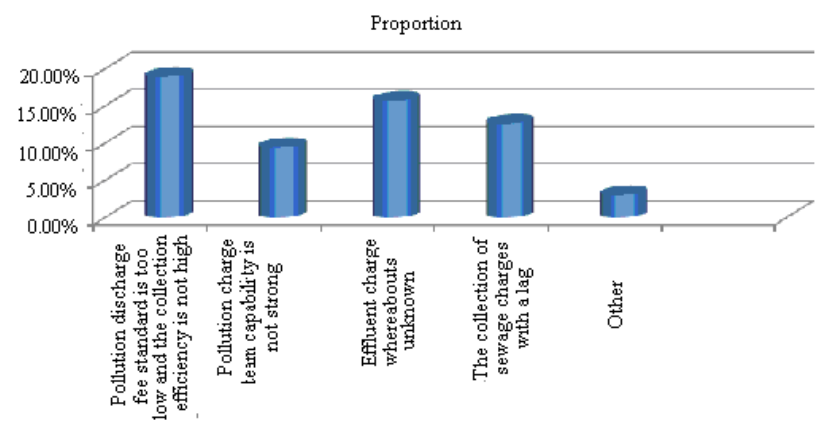

Figure 2. Chinese current pollution charge system defect analysis diagram

\section{Conclusion}

Based on the above analysis, it can be draw some improve existing environment-related taxes collection and management work's countermeasures and suggestions, as follows:

(1) To further improve related legal system with environmental tax collection and management. In the process of environmental tax collection and management, it must have relevant law as security. China should fully draw legislative experience of developed countries, then according to our country specific circumstances, such since, China's environmental protection work can begin from current awareness of environmental protection, to further rise legal level; for the taxpayers, it can play great restraint function. Not only that, the collection and management people will be provided an important guarantee legal framework for the collection and management process. On the basis of PRC Environmental protection law, the tax inspection method, tax agent method, invoice management law and other laws as supporting, so as to achieve laws to go and punish all offenders in tax collection.

(2) To establish unification of China environment tax system and perfect market system. China taxes are levied fee and tax by the environmental protection department and the tax department, which have not been able to adapt the need of sustainable development strategy. The independent environmental taxes is very necessary to set up in China, which can reduce or even eliminate the environmental protection related to lack of law enforcement as well as human collection, consultation charge and excess retention and other illegal phenomenon.

(3) Government departments need to further strengthen the propaganda work of environmental tax. Developed countries attach importance to improve people's awareness of environmental protection, so environmental initiatives can also obtain the national support and understanding. At the same time, the government should strengthen the communication and contact with enterprise, establishing supervision concept, strengthening comprehensive law enforcement, improving reward and punishment mechanism, increasing the illegal enterprises taxes, encouraging enterprises to reduce the cost of pollution control, full supporting green industry.

(4) To enhance tax staff quality. State taxation administration departments can adopt a variety of measures, it can organize the tax personnel training, so that a large number of high-quality professional and technical personnel enter into the tax management team, establishing and perfect the tax collecting authority internal checks and balances mechanism and supervision mechanism of 
tax again; at the same time, we should strengthen the coordination works between environmental protection department and tax departments, to make comparative advantage to more play, the maximum extent possible to save costs, so that environmental tax collection pattern can run a scientific, standardized and legalized track.

(5) The collection of funds implements transparency. Financial transparency can effectively guarantee government and official duties. According to the survey data shows, $45.4 \%$ of the employees are very concerned about the whereabouts of taxes, the tax transparency, strengthening the supervision of the government, which also can make the enterprise more believe government, efforts to cooperate with the government's tax collection issues; for the government, it also will produce positive effect. The tax transparency can make better communication between government and enterprises, at the same time can make the government timely understanding of social dynamics; not only can alleviate the government and the public in the strained relations of financial problems, but also more make the government really do service to the public, to promote the harmonious development of society forward.

\section{Acknowledgments}

The research was supported by the Innovation Training Program Fund of National College and University Students with the project number 111049138.

\section{References}

[1] ZhaoYan. Theoretical reflection and practical choice on Chinese environmental tax [D]. Guangxi normal university, 2010.

[2] FuBoYing.Theory suitable for China's environmental tax model[J]. Modern finance and economics ( Tianjin university of finance economics ), 2009 (11): 9-13.

[3] XuYan, WuYueqian. Theory on the environment tax levy and collection [J]. Eenvironmental science and management, 2011 (9):37-40.

[4] DongZhanfeng, GeChaZhong, GaoShuTing. On Chinese environmental tax reform[J]. Environmental protection and recycling economy, 2010 (10): 4-6.

[5] YangLaiFa; Swedish tax system and the reference [J]. Foreign-related taxation, 2009 (11): 112113.

[6] LiYongGang, AnJianHua, QinHongPu. Reality of pollutant emission property right transaction and the necessary of levying pollution tax [J]. Technology and industry, 2009 (10): 145-146.

[7] WuYanFang. Green taxation and economy sustainable development [J]. Tax research, 2009 (10):132-133.

[8] DengZiJi, HanYu. The tax system design of promoting circular economy development [J]. Tax research, 2010(3): 156-157.

[9] ZhangAiZhu. Construction of Chinese green tax system [J]. Tax research, 2010 (7): 143-144.

[10] GuoNa, LiuQiang. Draw lessons from developed country experience to promote China's green tax process [J]. Tax research, 2009 (1): 145-146.

[11] LiAnZe. Reflections on the establishment of green tax system [J]. China tax, 2010 (9): 8990.

[12] ZhaoJiHong. Study of China's environmental economic policy system and its construction [J]. Economic issues, 2009 (5): 125-126. 